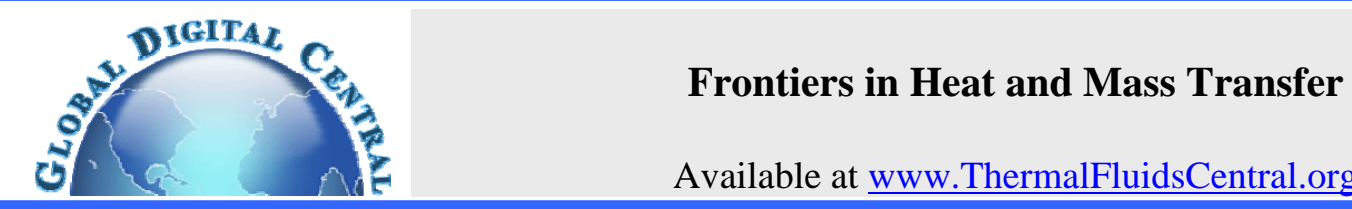

\title{
THERMAL DIFFUSION AND RADIATION EFFECTS ON UNSTEADY FREE CONVECTION FLOW IN THE PRESENCE OF MAGNETIC FIELD FIXED RELATIVE TO THE FLUID OR TO THE PLATE
}

\author{
B. Rushi Kumar*, T. Sravan Kumar, A .G Vijaya Kumar \\ Fluid Dynamics Division, School of Advanced Sciences, VIT University, Vellore, TN, 632014, India
}

\begin{abstract}
The objective of this study is to investigated thermal diffusion and radiation effects on unsteady free convection chemically reacting fluid flow past an accelerated infinite inclined plate with variable temperature and mass diffusion under the influence of uniform transverse magnetic field when the magnetic lines of force are fixed relative to the fluid or to the plate studied in two cases, (i) when magnetic field fixed relative to the fluid ( $K=0$ ), (ii) and the magnetic field fixed relative to the plate $(K=1)$ have been considered. A general exact solution of the dimensionless governing partial differential equation is obtained by the usual Laplace transform technique without any restriction. The effect of flow parameters on velocity, temperature, concentration, heat transfer and the rate of mass transfer are studied though graphs and tables.

Keywords: Soret effect, magnetic field, heat and mass transfer, radiation, free convection, inclined plate and chemical reaction.
\end{abstract}

\section{INTRODUCTION}

The study of magneto hydro dynamics with heat and mass transfer in the presence of radiation and diffusion has attracted the attention of a large number of scholars due to diverse applications. However, when the flow of mass caused by a temperature gradient, the Soret effect is corresponds to species differential equation developing in an initial homogeneous mixer submitted to a thermal gradient and the Dufour corresponds to the heat flux produced by concentration gradient, one cannot neglect the Soret effect. This is also called as thermal-diffusion effect. This type of problem is useful for isotope separation and in mixtures between gasses with very light molecular weight. In free convection flow the study of effect of magnetic field play a major role in liquid metals, electrolytes and ionized gasses etc. In power engineering, the thermal physics of hydro magnetic problems with the mass transfer have enormous applications. Radiative flows are faced with in many industrial and environment processes, heating and cooling chambers, fossil fuel combustion energy processes astrophysical, solar technology, evaporation from large open water reservoirs, In manufacturing industry, for the design of fins, steel rolling, nuclear power plant, gas turbines, various propulsive devices for aircrafts, missiles, satellites, combustion, energy utilization, temperature measurements, remote sensing for Astronomy, in Astrophysics and Geophysics and so on.

Stokes (1851) first studied the flow of an incompressible, viscous fluid past an impulsively started infinite plate in its own plane. The corresponding problem for infinite vertical plate moving impulsively in upward direction was studied by Soundalgekar (1977). MHD effects on impulsively started vertical infinite plate with variable temperature in the presence of transverse magnetic field were studied by Soundalgekar et al. (1981). The effects of transversely applied magnetic field, on the flow of an electrically conducting fluid past an impulsively started infinite isothermal vertical plate were also studied by Soundalgekar et al. (1979). The dimensionless governing equations were solved using Laplace transform technique. Kumari and nath (1999) analyzed the development of a symmetric flow of a viscous electrically conducting fluid in the forward stagnation point region of a two-dimensional body and over a stretching surface was set into impulsive motion from the rest. Muthucumaraswamy and Janakiraman (2006) studied MHD and radiation effects on moving isothermal vertical plate with variable and mass diffusion. The radiative free convection flow of optically thin gray-gas past semi-infinite vertical plate was studied by Soundalgekar and Takhar(1993). Raptis and Perdikis (1999) analyzed radiation and free convection flow past a moving plate. Narahari and Debnath (2013) studied unsteady magneto hydrodynamic free convection flow past an accelerated vertical plate. Tokis (1985) investigated exact solutions of the unsteady magneto hydrodynamic free convection flows. Das et al. (1996) have considered radiation effects on flow past an impulsively started infinite isothermal vertical plate. Kafoussias (1992) studied MHD thermal diffusion effects on free convection and mass transfer flow over an infinite vertical moving plate.

Alam and Sattar (1999) have discussed the thermal-diffusion effect on MHD free convection and mass transfer flow. Jha and Singh (1990) have analyzed the importance of the effect of thermal-diffusion. Alam et al. (2005) studied combined free convection and mass transfer flow past a vertical plate with heat generation and Soret effect through porous medium. Alam et al. (2006) analyzed the Soret effect on unsteady MHD free convection and mass transfer flow past an impulsively started vertical porous plate. Kumar and Varma (2011) studied thermal diffusion and radiation effects on unsteady MHD flow past an impulsively started exponentially accelerated vertical plate with variable temperature and variable mass diffusion. Kumar et al. (2012) studied thermal diffusion and radiation effects on unsteady MHD flow past an exponentially accelerated vertical plate with variable temperature and mass diffusion in the presence of heat source/sink. Rajesh and Varma (2009) studied thermal and radiation effects on MHD flow past an infinite vertical plate with variable temperature and

\footnotetext{
*Corresponding author. Email: rushikumar@vit.ac.in
} 
mass diffusion. The combined heat and mass transfer problem with chemical reaction are of importance in many processes, and therefore have received a considerable amount of attention in recent years. In processes, such as drying, evaporation at the surface of a water body, energy transfer in a wet cooling tower and the flow in a desert cooler, the heat and mass transfer occurs simultaneously. Chemical reactions can be codified as either homogeneous process or heterogeneous process. A homogeneous reaction is one that occurs uniformly though a given phase. In contrast, a heterogeneous reaction takes place in a restricted region or within the boundary of a phase. A reaction is said to be the first order if the rate of reaction is directly proportional to the concentration itself. In many chemical engineering processes, a chemical reaction between a foreign mass and the fluid flows occur. These processes take place in numerous industrial applications, such as the polymer production, the manufacturing of ceramics or glassware, the food processing etc. Pera and Gebhart (1971) analyzed the stability of laminar plumes by using some numerical solution and experiments. Hossian and Takhar (1996) studied radiation effect on mixed convection along a vertical plate with uniform surface temperature, heat and mass transfer. Raptis and singh (1983) analyzed the free convection flow of a viscous incompressible fluid past an infinite vertical plate embedded in porous medium with constant heat flux in the presence of transverse magnetic field.

However, in the literature we found less attention was paid on unsteady MHD free convection flows past an inclined plate subjected to a variable temperature and uniform mass diffusion with Soret effect when the magnetic lines being fixed relative to the fluid or when the magnetic lines being fixed relative to the plate even though this situation involves in many engineering applications. Chandran et al.(1998) was investigated the effects of magnetic field and buoyancy force on the unsteady free convection laminar flow of an electrically conducting fluid when the flow was generated by uniformly accelerated motion of an infinite vertical plate subjected to constant heat flux. They obtained exact solution with the help of Laplace transform technique and the numerical results were computed with the approximated error functions appeared in the solution.

In this paper, it is proposed to study thermal diffusion and radiation effects on free convection flow past an accelerated infinite inclined plate with variable temperature heat and mass diffusion discussed in two cases. Case (i) when the magnetic field relative to the fluid $(K=0)$ and case (ii) the magnetic field fixed relative to the plate $(K=1)$ in the presence of transverse applied magnetic field and a first order chemical reaction. The dimensionless governing equations are solved using Laplace transform technique and the solutions are expressed in terms of exponential and complementary error functions.

\section{MATHEMATICAL ANALYSIS}

In this paper, we study the effects of radiation and thermal-diffusion on unsteady MHD free convection of flow of a viscous incompressible, electrically, conducting, radiating fluid past an impulsively started infinite inclined plate with variable temperature and mass diffusion in the presence of transverse applied magnetic field fixed relative to the fluid or to the plate. The $\mathrm{x}^{\prime}$-axis is taken along the plate in vertical upward direction and $\mathrm{y}^{\prime}$-axis is taken normal to it in the direction of applied transverse magnetic field. Initially, it is assumed that the plate and surrounding fluid are at the same temperature and concentration in stationary condition for all the points in entire flow region $y^{\prime} \geq 0$. At time $t^{\prime} \geq 0$, the plate is given an impulsive motion with velocity $u=u_{0} \exp \left(a^{\prime} t^{\prime}\right)$ in its own plane. At the same time, the plate temperature is raised linearly with time $t$ and also the mass is diffused from the plate linearly with time t. A magnetic field of uniform strength $\mathrm{B}_{0}$ is assumed to be applied normal to the direction of the flow and the induced magnetic field is assumed to be neglected as the magnetic Reynolds number of the flow is taken to be very small.

For free convection flow, it is also assumed that,
- $\quad$ The viscous dissipation is neglected in the energy equation.

- $\quad$ The effects of variation in density ( $\rho$ ) with temperature and species concentration are considered only on the body force term, in accordance with usual Boussinesq approximation.

- $\quad$ The fluid considered here is gray, absorbing / emitting radiation but a non-scattering medium.

- $\quad$ Since the flow of the fluid is assumed to be in the direction of $\mathrm{x}^{\prime}$ axis, so the physical quantities are functions of the space co-ordinate $\mathrm{y}^{\prime}$ and $\mathrm{t}^{\prime}$ only.

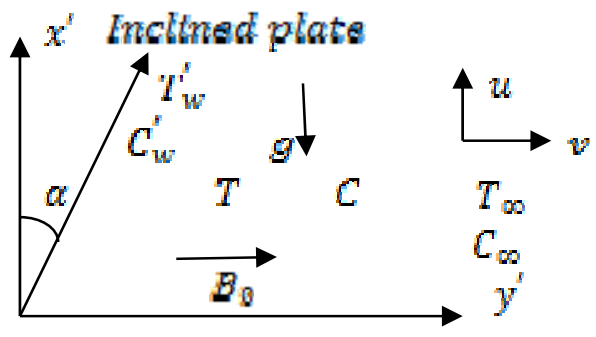

Fig. 1 Physical co-ordinate system

Then by usual Boussinesq's approximation, the flow governed by the following equations:

$$
\begin{aligned}
& \frac{\partial u^{\prime}}{\partial t^{\prime}}=g \beta\left(T^{\prime}-T_{\infty}^{\prime}\right) \cos \alpha+g \beta^{*}\left(C^{\prime}-C_{\infty}^{\prime}\right) \cos \alpha+v \frac{\partial^{2} u^{\prime}}{\partial y^{\prime 2}}-\frac{\sigma \beta_{0}^{2} u^{\prime}}{\rho} \\
& \rho c_{p} \frac{\partial T^{\prime}}{\partial t^{\prime}}=k \frac{\partial^{2} T^{\prime}}{\partial y^{\prime 2}}-\frac{\partial q_{r}}{\partial y^{\prime}}+Q^{\prime}\left(T_{\infty}^{\prime}-T^{\prime}\right) \\
& \frac{\partial C^{\prime}}{\partial t^{\prime}}=D \frac{\partial^{2} C^{\prime}}{\partial y^{\prime 2}}+D_{1} \frac{\partial^{2} T^{\prime}}{\partial y^{\prime 2}}-k^{\prime}\left(C^{\prime}-C_{\infty}^{\prime}\right)
\end{aligned}
$$

If the magnetic field fixed relative to the plate, the momentum equation (1) is replaced by [ Camer (1973), Raptis (1983), and Tokies (1985)]

$$
\begin{array}{r}
\frac{\partial u^{\prime}}{\partial t^{\prime}}=g \beta\left(T^{\prime}-T_{\infty}^{\prime}\right) \cos \alpha+g \beta^{*}\left(C^{\prime}-C_{\infty}^{\prime}\right) \cos \alpha+v \frac{\partial^{2} u^{\prime}}{\partial y^{\prime 2}} \\
-\frac{\sigma \beta_{0}^{2} u^{\prime}}{\rho}\left[u^{\prime}-u_{0} f\left(t^{\prime}\right)\right]
\end{array}
$$

Combining (1) and (4)

$$
\begin{aligned}
\frac{\partial u^{\prime}}{\partial t^{\prime}}=g \beta\left(T^{\prime}-T_{\infty}^{\prime}\right) \cos \alpha+ & g \beta^{*}\left(C^{\prime}-C_{\infty}^{\prime}\right) \cos \alpha+v \frac{\partial^{2} u^{\prime}}{\partial y^{\prime 2}} \\
& -\frac{\sigma \beta_{0}^{2} u^{\prime}}{\rho}\left[u^{\prime}-K u_{0} f\left(t^{\prime}\right)\right]
\end{aligned}
$$

where $K=\left\{\begin{array}{l}0 \text { if } B_{0} \text { is fixed relative to the fluid } \\ 1 \text { if } B_{0} \text { is fixed relative to the plate }\end{array}\right.$

For an exponentially accelerated plate, $f\left(t^{\prime}\right)=\exp \left(a_{0}^{\prime} t^{\prime}\right)$,

where $a_{0}^{\prime}$ is dimensional accelerating parameter.

with the following initial and boundary conditions

$$
\begin{array}{r}
t^{\prime} \leq 0: u^{\prime}=0, \quad T^{\prime}=T_{\infty}^{\prime}, \quad C^{\prime}=C_{\infty}^{\prime}, \quad \text { for all } y^{\prime} \\
t^{\prime}>0: u^{\prime}=u_{0} \exp \left(a^{\prime} t^{\prime}\right), T^{\prime}=T_{\infty}^{\prime}+\left(T_{w^{\prime}}^{\prime}-T_{\infty}^{\prime}\right) A t^{\prime}, C^{\prime}=C_{\infty}^{\prime}+\left(C_{w^{\prime}}^{\prime}-C_{\infty}^{\prime}\right) A t^{\prime} \\
\text { at } y^{\prime}=0
\end{array}
$$




$$
u^{\prime}=0, \quad T^{\prime} \rightarrow T_{\infty}^{\prime}, \quad C^{\prime} \rightarrow C_{\infty}^{\prime}, \quad \text { as } \quad y^{\prime} \rightarrow \infty
$$

where $A=\frac{u_{0}^{2}}{v}$ the local radiant for the case of an optically thin gray gas is expressed by $\frac{\partial q_{r}}{\partial y^{\prime}}=-4 a^{*} \sigma\left(T_{\infty}^{\prime 4}-T^{\prime 4}\right)$

It is assumed that the temperature differences within the flow are sufficiently small and that $T^{4}$ may be expressed as a linear function of the temperature. This is obtained by expanding $T^{\prime 4}$ in a Taylor series about $\mathrm{T}_{\infty}^{\prime}$ and neglecting the higher order terms, thus we get

$T^{\prime 4} \cong 4 T_{\infty}^{\prime 3} T^{\prime}-3 T_{\infty}^{\prime 4}$

From Esq. (5) and (6), Eq. (2) reduces to

$\rho c_{p} \frac{\partial T^{\prime}}{\partial t^{\prime}}=k \frac{\partial^{2} T^{\prime}}{\partial t^{\prime 2}}+16 a^{*} \sigma T_{\infty}^{\prime 3}\left(T_{\infty}^{\prime}-T^{\prime}\right)$

on introducing the following non- dimensional quantities

$u=\frac{u^{\prime}}{u_{0}}, t=\frac{t^{\prime} u_{0}^{2}}{v}, y=\frac{y^{\prime} u_{0}}{v}, \theta=\frac{T^{\prime}-T_{\infty}^{\prime}}{T_{w}^{\prime}-T_{\infty}^{\prime}}, k=\frac{u_{0}^{2} k^{\prime}}{v^{2}}$,

$C=\frac{C^{\prime}-C_{\infty}^{\prime}}{C_{W}^{\prime}-C_{\infty}^{\prime}}, G r=\frac{g \beta v\left(T_{W}^{\prime}-T_{\infty}^{\prime}\right)}{u_{0}^{3}}, G m=\frac{g \beta^{*} v\left(C_{w}^{\prime}-C_{\infty}^{\prime}\right)}{u_{0}^{3}}, \operatorname{Pr}=\frac{\mu C_{\rho}}{k}, S c=\frac{v}{D}$,

$S_{O}=\frac{D_{1}\left(T_{w}^{\prime}-T_{\infty}^{\prime}\right)}{v\left(C_{w}^{\prime}-C_{\infty}^{\prime}\right)}, M=\frac{\sigma B_{0}^{2} v}{\rho u_{0}^{2}}, R=\frac{16 a^{*} v^{2} \sigma T_{\infty}^{3}}{k u_{0}^{2}}, H=\frac{Q^{\prime} v^{2}}{k u_{0}^{2}}$,

we get the following governing equations which are dimensionless.

$\frac{\partial u}{\partial t}=\frac{\partial^{2} u}{\partial y^{2}}+G r \theta \cos \alpha+G m C \cos \alpha-M\left(u-K e^{a} 0^{t}\right)$

$\frac{\partial \theta}{\partial t}=\frac{1}{\operatorname{Pr}} \frac{\partial^{2} \theta}{\partial y^{2}}-\frac{1}{\operatorname{Pr}}(R+H) \theta$

$\frac{\partial C}{\partial t}=\frac{1}{S c} \frac{\partial^{2} C}{\partial y^{2}}+S_{O} \frac{\partial^{2} \theta}{\partial y^{2}}-k C$

The initial and boundary conditions in dimensionless form are as follows:

$t^{\prime} \leq 0: \quad u=0, \quad \theta=0, \quad C=0 \quad$ for all $y$,

$t>0: \quad u=\exp \left(a_{0} t\right), \quad \theta=t, \quad C=t \quad$ at $\quad y=0$,

$u \rightarrow 0, \quad \theta \rightarrow 0, \quad C \rightarrow 0 \quad$ as $\quad y \rightarrow \infty$

The appeared physical parameters are defined in the nomenclature.

\section{METHOD OF SOLUTION}

The dimensionless governing equations form (11) to (13), subject to the boundary conditions (14) are solved by usual Laplace transform technique and the solutions are expressed in terms of exponential and complementary error functions

$C(y, t)=a_{7}\left[\begin{array}{l}\left(\frac{t}{2}+\frac{y \sqrt{S c}}{4 \sqrt{k}}\right) \exp (y \sqrt{k S c}) \operatorname{erfc}\left(\frac{y \sqrt{S c}}{2 \sqrt{t}}+\sqrt{k t}\right) \\ +\left(\frac{t}{2}-\frac{y \sqrt{S c}}{4 \sqrt{k}}\right) \exp (-y \sqrt{k S c}) \operatorname{erfc}\left(\frac{y \sqrt{S c}}{2 \sqrt{t}}-\sqrt{k t}\right)\end{array}\right]$ $+\frac{a_{8}}{2}\left[\begin{array}{l}\exp (y \sqrt{k S c}) \operatorname{erfc}\left(\frac{y \sqrt{S c}}{2 \sqrt{t}}+\sqrt{k t}\right) \\ +\exp (-y \sqrt{k S c}) \operatorname{erfc}\left(\frac{y \sqrt{S c}}{2 \sqrt{t}}-\sqrt{k t}\right)\end{array}\right]$

$-\frac{a_{8}}{2} \exp \left(-a_{3} t\right)\left[\begin{array}{l}\exp \left(y \sqrt{\left(k-a_{3}\right)} S c\right) \operatorname{erfc}\left(\frac{y \sqrt{S c}}{2 \sqrt{t}}+\sqrt{\left(k-a_{3}\right) t}\right) \\ +\exp \left(-y \sqrt{\left(k-a_{3}\right)} S c\right) \operatorname{erfc}\left(\frac{y \sqrt{S c}}{2 \sqrt{t}}-\sqrt{\left(k-a_{3}\right) t}\right)\end{array}\right]$

$-\frac{a_{8}}{2}\left[\begin{array}{l}\exp (y \sqrt{E}) \operatorname{erfc}\left(\frac{y \sqrt{\mathrm{Pr}}}{2 \sqrt{t}}+\sqrt{\frac{E t}{\mathrm{Pr}}}\right) \\ +\exp (-y \sqrt{E}) \operatorname{erfc}\left(\frac{y \sqrt{\mathrm{Pr}}}{2 \sqrt{t}}-\sqrt{\frac{E t}{\mathrm{Pr}}}\right)\end{array}\right]$

$+a_{5}\left[\begin{array}{l}\left(\frac{t}{2}+\frac{y \operatorname{Pr}}{4 \sqrt{E}}\right) \exp (y \sqrt{E}) \operatorname{erfc}\left(\frac{y \sqrt{\mathrm{Pr}}}{2 \sqrt{t}}+\sqrt{\frac{E t}{\operatorname{Pr}}}\right) \\ +\left(\frac{t}{2}-\frac{y \operatorname{Pr}}{4 \sqrt{E}}\right) \exp (-y \sqrt{E}) \operatorname{erfc}\left(\frac{y \sqrt{\mathrm{Pr}}}{2 \sqrt{t}}-\sqrt{\frac{E t}{\operatorname{Pr}}}\right)\end{array}\right]$

$+\frac{a_{8}}{2} \exp \left(-a_{3} t\right)\left[\begin{array}{l}\exp \left(y \sqrt{E-a_{3} \operatorname{Pr}}\right) \operatorname{erfc}\left(\frac{y \sqrt{\mathrm{Pr}}}{2 \sqrt{t}}+\sqrt{\frac{E t}{\operatorname{Pr}}-a_{3} t}\right) \\ +\exp \left(-y \sqrt{E-a_{3} \operatorname{Pr}}\right) \operatorname{erfc}\left(\frac{y \sqrt{\operatorname{Pr}}}{2 \sqrt{t}}-\sqrt{\frac{E t}{\operatorname{Pr}}-a_{3} t}\right)\end{array}\right]$

$\theta(y, t)=\left[\begin{array}{l}\left(\frac{t}{2}+\frac{y \operatorname{Pr}}{4 \sqrt{E}}\right) \exp (y \sqrt{E}) \operatorname{erfc}\left(\frac{y \sqrt{\operatorname{Pr}}}{2 \sqrt{t}}+\sqrt{\frac{E t}{\operatorname{Pr}}}\right) \\ +\left(\frac{t}{2}-\frac{y \operatorname{Pr}}{4 \sqrt{E}}\right) \exp (-y \sqrt{E}) \operatorname{erfc}\left(\frac{y \sqrt{\operatorname{Pr}}}{2 \sqrt{t}}-\sqrt{\frac{E t}{\operatorname{Pr}}}\right)\end{array}\right]$

$u(y, t)=\frac{A_{1}}{2} \exp \left(a_{0} t\right)\left[\begin{array}{l}\exp \left(y \sqrt{M+a_{0}}\right) \operatorname{erfc}\left(\frac{y}{2 \sqrt{t}}+\sqrt{\left(M+a_{0}\right)} t\right) \\ +\exp \left(-y \sqrt{M+a_{0}}\right) \operatorname{erfc}\left(\frac{y}{2 \sqrt{t}}-\sqrt{\left(M+a_{0}\right)} t\right)\end{array}\right]$

$+A_{2}\left[\left(\frac{t}{2}+\frac{y}{4 \sqrt{M}}\right) \exp (y \sqrt{M}) \operatorname{erfc}\left(\frac{y}{2 \sqrt{t}}+\sqrt{M t}\right)\right.$

$\left[+\left(\frac{t}{2}-\frac{y}{4 \sqrt{M}}\right) \exp (-y \sqrt{M}) \operatorname{erfc}\left(\frac{y}{2 \sqrt{t}}-\sqrt{M t}\right)\right]$

$+\frac{A_{3}}{2}\left[\begin{array}{l}\exp (y \sqrt{M}) \operatorname{erfc}\left(\frac{y}{2 \sqrt{t}}+\sqrt{M t}\right) \\ +\exp (-y \sqrt{M}) \operatorname{erfc}\left(\frac{y}{2 \sqrt{t}}-\sqrt{M t}\right)\end{array}\right]$

$+\frac{A_{4}}{2} \exp \left(-a_{3} t\right)\left[\begin{array}{l}\exp \left(y \sqrt{M-a_{3}}\right) \operatorname{erfc}\left(\frac{y}{2 \sqrt{t}}+\sqrt{\left(M-a_{3}\right)} t\right) \\ +\exp \left(-y \sqrt{M-a_{3}}\right) \operatorname{erfc}\left(\frac{y}{2 \sqrt{t}}-\sqrt{\left(M-a_{3}\right)} t\right)\end{array}\right]$

$+\frac{A_{5}}{2} \exp \left(-a_{10} t\right)\left[\begin{array}{l}\exp \left(y \sqrt{M-a_{10}}\right) \operatorname{erfc}\left(\frac{y}{2 \sqrt{t}}+\sqrt{\left(M-a_{10}\right)} t\right) \\ +\exp \left(-y \sqrt{M-a_{10}}\right) \operatorname{erfc}\left(\frac{y}{2 \sqrt{t}}-\sqrt{\left(M-a_{10}\right)} t\right)\end{array}\right]$

$+\frac{A_{6}}{2} \exp \left(-a_{12} t\right)\left[\begin{array}{l}\exp \left(y \sqrt{M-a_{12}}\right) \operatorname{erfc}\left(\frac{y}{2 \sqrt{t}}+\sqrt{\left(M-a_{12}\right)} t\right) \\ +\exp \left(-y \sqrt{M-a_{12}}\right) \operatorname{erfc}\left(\frac{y}{2 \sqrt{t}}-\sqrt{\left(M-a_{12}\right)} t\right)\end{array}\right]$

$+A_{7} \exp (-M t) \operatorname{erfc}\left(\frac{y}{2 \sqrt{t}}\right)$ 


$$
\begin{aligned}
& +\frac{A_{8}}{2}\left[\begin{array}{l}
\exp (y \sqrt{k S c}) \operatorname{erfc}\left(\frac{y \sqrt{S c}}{2 \sqrt{t}}+\sqrt{k t}\right) \\
+\exp (-y \sqrt{k S c}) \operatorname{erfc}\left(\frac{y \sqrt{S c}}{2 \sqrt{t}}-\sqrt{k t}\right)
\end{array}\right] \\
& +A_{9}\left[\begin{array}{l}
\left(\frac{t}{2}+\frac{y \sqrt{S c}}{4 \sqrt{k}}\right) \exp (y \sqrt{k S c}) \operatorname{erfc}\left(\frac{y \sqrt{S c}}{2 \sqrt{t}}+\sqrt{k t}\right) \\
+\left(\frac{t}{2}-\frac{y \sqrt{S c}}{4 \sqrt{k}}\right) \exp (-y \sqrt{k S c}) \operatorname{erfc}\left(\frac{y \sqrt{S c}}{2 \sqrt{t}}-\sqrt{k t}\right)
\end{array}\right] \\
& +\frac{A_{10}}{2} \exp \left(-a_{3} t\right)\left[\begin{array}{l}
\exp \left(y \sqrt{\left(k-a_{3}\right)} S c\right) \operatorname{erfc}\left(\frac{y \sqrt{S c}}{2 \sqrt{t}}+\sqrt{\left(k-a_{3}\right) t}\right) \\
+\exp \left(-y \sqrt{\left(k-a_{3}\right)} \operatorname{Sc}\right) \operatorname{erfc}\left(\frac{y \sqrt{S c}}{2 \sqrt{t}}-\sqrt{\left(k-a_{3}\right) t}\right)
\end{array}\right] \\
& -\frac{A_{6}}{2} \exp \left(-a_{12} t\right)\left[\begin{array}{l}
\exp \left(y \sqrt{\left(k-a_{12}\right)} S c\right) \operatorname{erfc}\left(\frac{y \sqrt{S c}}{2 \sqrt{t}}+\sqrt{\left(k-a_{12}\right) t}\right) \\
+\exp \left(-y \sqrt{\left(k-a_{12}\right)} S c\right) \operatorname{erfc}\left(\frac{y \sqrt{S c}}{2 \sqrt{t}}-\sqrt{\left(k-a_{12}\right) t}\right)
\end{array}\right] \\
& +\frac{A_{11}}{2}\left[\begin{array}{l}
\exp (y \sqrt{E}) \operatorname{erfc}\left(\frac{y \sqrt{\mathrm{Pr}}}{2 \sqrt{t}}+\sqrt{\frac{E t}{\mathrm{Pr}}}\right) \\
+\exp (-y \sqrt{E}) \operatorname{erfc}\left(\frac{y \sqrt{\mathrm{Pr}}}{2 \sqrt{t}}-\sqrt{\frac{E t}{\mathrm{Pr}}}\right)
\end{array}\right] \\
& +A_{12}\left[\begin{array}{l}
\left(\frac{t}{2}+\frac{y \operatorname{Pr}}{4 \sqrt{E}}\right) \exp (y \sqrt{E}) \operatorname{erfc}\left(\frac{y \sqrt{\mathrm{Pr}}}{2 \sqrt{t}}+\sqrt{\frac{E t}{\operatorname{Pr}}}\right) \\
+\left(\frac{t}{2}-\frac{y \operatorname{Pr}}{4 \sqrt{E}}\right) \exp (-y \sqrt{E}) \operatorname{erfc}\left(\frac{y \sqrt{\mathrm{Pr}}}{2 \sqrt{t}}-\sqrt{\frac{E t}{\operatorname{Pr}}}\right)
\end{array}\right] \\
& +\frac{A_{13}}{2} \exp \left(-a_{3} t\right)\left[\begin{array}{l}
\exp \left(y \sqrt{E-a_{3} \operatorname{Pr}}\right) \operatorname{erfc}\left(\frac{y \sqrt{\operatorname{Pr}}}{2 \sqrt{t}}+\sqrt{\frac{E t}{\operatorname{Pr}}-a_{3} t}\right) \\
+\exp \left(-y \sqrt{E-a_{3} \operatorname{Pr}}\right) \operatorname{erfc}\left(\frac{y \sqrt{\operatorname{Pr}}}{2 \sqrt{t}}-\sqrt{\frac{E t}{\operatorname{Pr}}-a_{3} t}\right)
\end{array}\right] \\
& +\frac{A_{14}}{2} \exp \left(-a_{10} t\right)\left[\begin{array}{l}
\exp \left(y \sqrt{E-a_{10} \operatorname{Pr}}\right) \operatorname{erfc}\left(\frac{y \sqrt{\operatorname{Pr}}}{2 \sqrt{t}}+\sqrt{\frac{E t}{\operatorname{Pr}}-a_{10} t}\right) \\
+\exp \left(-y \sqrt{E-a_{10} \operatorname{Pr}}\right) \operatorname{erfc}\left(\frac{y \sqrt{\operatorname{Pr}}}{2 \sqrt{t}}-\sqrt{\frac{E t}{\operatorname{Pr}}-a_{10} t}\right)
\end{array}\right] \\
& +A_{7} \exp \left(a_{0} t\right)\left[\begin{array}{l}
\exp \left(y \sqrt{M+a_{0}}\right) \operatorname{erfc}\left(\frac{y}{2 \sqrt{t}}+\sqrt{\left(M+a_{0}\right)} t\right) \\
+\exp \left(-y \sqrt{M+a_{0}}\right) \operatorname{erfc}\left(\frac{y}{2 \sqrt{t}}-\sqrt{\left(M+a_{0}\right)} t\right)
\end{array}\right]
\end{aligned}
$$

where

$\mathrm{E}=\mathrm{R}+\mathrm{H}, a_{1}=\frac{-S c S_{0}}{\operatorname{Pr}(\operatorname{Pr}-S c)}, a_{2}=\frac{E}{\operatorname{Pr}}, a_{3}=\frac{E-k S c}{\operatorname{Pr}-S c}, a_{4}=\frac{a_{1} a_{2}}{a_{3}^{2}}$

$, a_{5}=\frac{a_{1} a_{2}}{a_{3}}, a_{6}=\frac{a_{1}}{a_{3}}, a_{7}=\left(1-a_{5}\right), a_{8}=\left(a_{4}-a_{6}\right)$,

$a_{9}=\frac{-G r \cos \alpha}{\operatorname{Pr}-1}, a_{10}=\frac{E-M}{\operatorname{Pr}-1}, a_{11}=\frac{G m \cos \alpha}{S c-1}, a_{12}=\frac{k S c-M}{S c-1}$,

$a_{13}=\frac{G m \cos \alpha}{\operatorname{Pr}-1}, a_{14}=\frac{a_{9}}{a_{10}^{2}}, a_{15}=\frac{a_{9}}{a_{10}}, a_{16}=\frac{a_{11}}{a_{12}^{2}}$

$a_{17}=\frac{a_{11}}{a_{12}}, a_{18}=\frac{a_{1} a_{2} a_{11}\left(a_{3}+a_{12}\right)}{a_{3}^{2} a_{12}^{2}}, a_{19}=\frac{a_{1} a_{2} a_{11}}{a_{3} a_{12}}$,

$a_{20}=\frac{a_{1} a_{2} a_{11}}{a_{3}^{2}\left(a_{12}-a_{3}\right)}, a_{21}=\frac{a_{1} a_{2} a_{11}}{a_{12}^{2}\left(a_{12}-a_{3}\right)}, a_{22}=\frac{a_{1} a_{11}}{a_{12} a_{3}}$,

$a_{23}=\frac{a_{1} a_{11}}{a_{3}\left(a_{12}-a_{3}\right)}, \quad a_{24}=\frac{a_{1} a_{11}}{a_{12}\left(a_{12}-a_{3}\right)}, \quad a_{29}=\frac{a_{1} a_{13}}{a_{3} a_{10}}$,

$$
\begin{aligned}
& a_{26}=\frac{a_{1} a_{2} a_{13}}{a_{3} a_{10}}, a_{25}=\frac{a_{1} a_{2} a_{13}\left(a_{3}+a_{10}\right)}{a_{3}^{2} a_{10}^{2}}, a_{27}=\frac{a_{1} a_{2} a_{13}}{a_{3}^{2}\left(a_{10}-a_{3}\right)}, \\
& a_{28}=\frac{a_{1} a_{2} a_{13}}{a_{10}^{2}\left(a_{10}-a_{3}\right)}, a_{30}=\frac{a_{1} a_{13}}{a_{3}\left(a_{10}-a_{3}\right)}, a_{31}=\frac{a_{1} a_{13}}{a_{10}\left(a_{10}-a_{3}\right)}, \\
& a_{32}=\frac{M K}{M+a_{0}}, A_{1}=\left(1-a_{32}\right), A_{2}=\left(-a_{15}+a_{17}-a_{19}+a_{26}\right) \\
& A_{3}=\left(a_{14}-a_{16}+a_{18}-a_{22}-a_{25}+a_{29}\right), \\
& A_{4}=\left(-a_{20}+a_{23}+a_{27}-a_{30}\right), A_{7}=a_{32} \\
& A_{5}=\left(-a_{14}-a_{28}+a_{31}\right), A_{6}=\left(a_{16}+a_{21}-a_{24}\right) \\
& A_{9}=\left(-a_{17}+a_{19}\right), A_{8}=\left(a_{16}-a_{18}+a_{22}\right), \\
& A_{10}=\left(a_{20}-a_{23}\right), A_{11}=\left(-a_{14}+a_{25}-a_{29}\right), A_{12}=\left(a_{15}-a_{26}\right), \\
& A_{13}=\left(-a_{27}+a_{30}\right), A_{14}=\left(a_{14}+a_{28}-a_{31}\right) .
\end{aligned}
$$

\section{Nusselt number:}

From temperature field, the Nusselt number which is given in non-dimensional form as follows:

$$
N u=-\left[\frac{\partial \theta}{\partial y}\right]_{y=0}
$$

From eqs. (16) and (18), we get Nusselt number as follows:

$$
N u=\left[t \sqrt{E} \operatorname{erf} \sqrt{\frac{E t}{\operatorname{Pr}}}+\sqrt{\frac{t \operatorname{Pr}}{\pi}} \exp \left(-\frac{E t}{\operatorname{Pr}}\right)+\frac{\operatorname{Pr}}{2 \sqrt{E}} \operatorname{erf} \sqrt{\frac{E t}{\operatorname{Pr}}}\right]
$$

\section{Sherwood number:}

From concentration field, Sherwood Number which is given in non -dimensional form as follows

$S h=-\left[\frac{\partial C}{\partial y}\right]_{y=0}$

From Eqs.(15) and (20) we get Sherwood Number as follows:

$$
\begin{aligned}
& S h=a_{7}\left[\exp (-k t) \sqrt{\frac{t S c}{\pi}}+t \sqrt{k S c} \operatorname{efr}(\sqrt{k t})+\frac{\sqrt{S c}}{2 \sqrt{k}} \operatorname{erf}(\sqrt{k t})\right] \\
& +a_{8}\left[\exp (-k t) \sqrt{\frac{S c}{\pi t}}-\sqrt{k S c} \operatorname{erf}(\sqrt{k t})\right] \\
& +a_{8} \exp \left(-a_{3} t\right)\left[-\exp \left(k t-a_{3} t\right) \sqrt{\frac{S c}{\pi t}}+\right. \\
& +a_{8}\left[\exp \left(-\frac{E t}{\operatorname{Pr}}\right) \sqrt{\frac{\operatorname{Pr}}{\pi t}}+\sqrt{E} \operatorname{erf}\left(\sqrt{\frac{E t}{\operatorname{Pr}}}\right)\right] \\
& -a_{5}\left[\exp \left(-\frac{E t}{\operatorname{Pr}}\right) \sqrt{\frac{\operatorname{Pr} t}{\pi}}+t \sqrt{E} \operatorname{erf}\left(\frac{E t}{\operatorname{Pr}}\right)+\frac{\operatorname{Pr}}{2 \sqrt{E}} \operatorname{erf}\left(\sqrt{\frac{E t}{\operatorname{Pr}}}\right)\right]
\end{aligned}
$$

\section{RESULT AND DISCUSSION}

To get a physical insight into the problem, the numerical evaluation of the analytical results reported in the previous section was performed and as set of results is reported graphically in Figs. 2 to 17. for the case of heating $(G r<0, G m<0)$ and cooling $(G r>0, G m>0)$ of the plate. The heating and cooling takes place by setting up free convection currents due to the temperature and concentration gradient. These results are obtained to reveal the effect of various physical parameters like radiation parameter $(R)$, heat source parameter $(H)$ magnetic parameter $(M)$, Schmidt parameter $(S c)$, Prandtl number $(P r)$, Soret number (So), thermal Grashof number $(\mathrm{Gr})$, mass Grashof number $(\mathrm{Gm})$ on the velocity, temperature and the concentration profiles. 
The velocity profiles for an exponentially accelerated plate are presented from Figs. 2. to 9, when the magnetic field is being fixed to the fluid $(K=0)$ discussed in case (i) and the magnetic field being fixed related though the plate $(K=1)$ discussed in case (ii).The effects of $M$, So, $G r, G m, S c, R, H$ and $t$ on the velocity field are shown from Fig. 2 to 9 , in the presence of radiation and first order chemical reaction respectively, when other parameters being fixed.

Figure 2 reveals that the effect of magnetic field parameter on fluid velocity and it is observed that an increase in magnetic parameter $M$, the velocity decreases in case of cooling and heating of the plate for $\mathrm{Pr}$ $=0.71$. It is due to the fact that the application of transverse magnetic field will result a Lorentz force similar to drag force, which tends to resist the fluid flow and thus reducing its velocity and Fig. 3, illustrates the effect of magnetic field parameter of the plate velocity and it is noticed that an increase in magnetic parameter $M$, the velocity increases in both cases of cooling and heating of the plate. It is seen that from Fig. 4, that the velocity increases with an increasing value of thermal diffusion parameter (So) in case of cooling of the plate and a reverse effect is observed in case of heating of the plate, when the magnetic field is being fixed to the fluid $(K=0)$. From Fig. 5, we observe that the velocity suddenly increases with an increasing value of thermal diffusion parameter (So) in case of cooling of the plate and a reverse effect it is noticed in case of heating of the plate, when the magnetic field being fixed related though the plate $(K=1)$.Fig. 6, illustrates the effects $G r$ and $G m$ on the velocity field. It is found that the velocity decreases with the increases of $\mathrm{Gr}$ and $\mathrm{Gm}$ in case of cooling and reverse effect is observed in case of heating, when the magnetic field is being fixed to the fluid $(K=0)$ and Fig. 7 , it is seen that the velocity fall down with the increase of $\mathrm{Gr}$ and $\mathrm{Gm}$ in case of cooling of the plate and reverse effects it is observed in the case of heating of the plate, when the magnetic field being fixed related though the plate $(K=1)$. Fig. 8, reveals the velocity increases with the increases of time $t$ in case of cooling of the plate and the trend is just reversed in the case of heating of the plate, for the magnetic field when it is being fixed to the fluid $(K=0)$ and from Fig. 9, it is observed that the velocity increases with the increases of time $t$ in case of cooling of the plate and reverse effects is noticed in the case of heating of the plate, for the magnetic field being when it is being fixed related though the plate $(K=1)$. In all above figures for both cases of cooling and heating of the plate for case (i) and case (ii) moving for away from the plate, the velocity profiles decreases slowly and tending to zero.

The influence of various flow parameters on the fluid temperature are illustrated in Figs. 10 and 11. From these Figs. 10 and 11, it is observed that as radiation parameter $R$, heat source parameter $H$ and Prandtl number $P r$ increases when the temperature of the flow field decreases. Concentration profiles for different values of $S c$, So, $R, H$, and $t$ are presented though Figs. 12, 13 and 14. From these Figs it is seen that the concentration increases with an increases in $S c$, or So, or $R$, or $H$ while it increases with time $t$. From Fig. 15, it is observed that concentration decreases with an increase in $k$ while it increases with time $t$. It is seen that from Fig. 16, Nusselt number increases with increasing values of $R$ for both water $(P r=7.0)$ and air $(P r=0.71)$. It is also observed that Nusselt number for water is higher than that of air. The reason is that small values of $\mathrm{Pr}$ are equivalent to increasing the thermal conductivities and therefore heat is able to diffuse away from the plate more rapidly than higher values of $\mathrm{Pr}$, hence the rate of heat transfer is reduced. Fig. 17, reveals the Sherwood number decreases with the increasing values of So.

The velocity profiles for different values of $R$ and $H$ when $K=0$ and $K=1$ in case of cooling and heating of the plate for fixed values of $S_{c}=2.01, \operatorname{Pr}=0.71, S_{o}=5, k=0.5$ and $t=0.2$, are shown in Table 1 and Table 2. It is observed from these tables that when $K=0$ velocity decreases with $y$ for both cooling and heating of the plate and when $K=1$ velocity increases up to certain $y$ value and thereafter velocity decreases for cooling of the plate while velocity decreases gradually in case of heating of the plate.

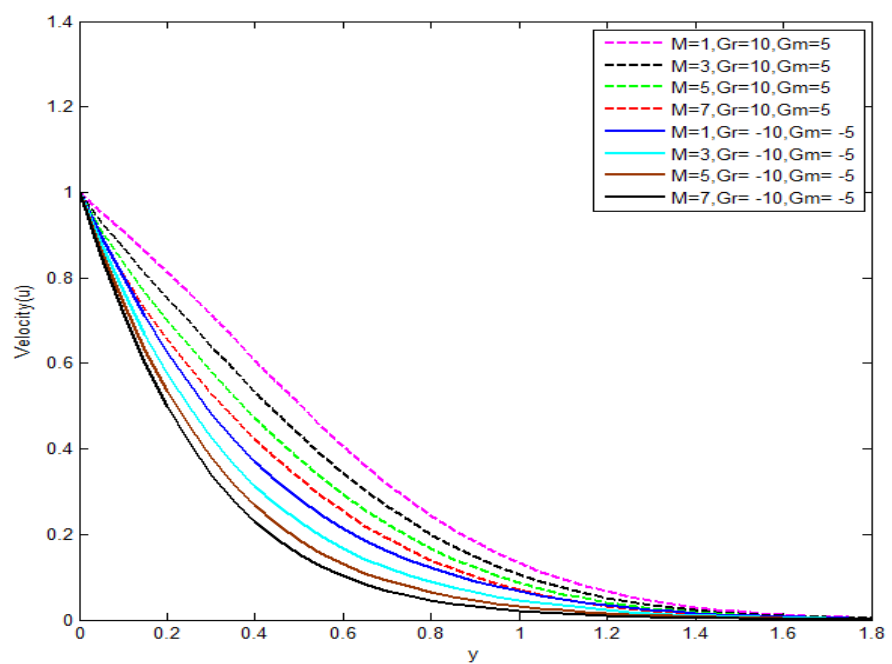

Fig. 2 Velocity profiles for different $M$ when $(K=0), S c=2.01$, So $=5, \operatorname{Pr}=0.71, R=10, a_{0}=0, k=0.5, H=4$ and $t=0.2$

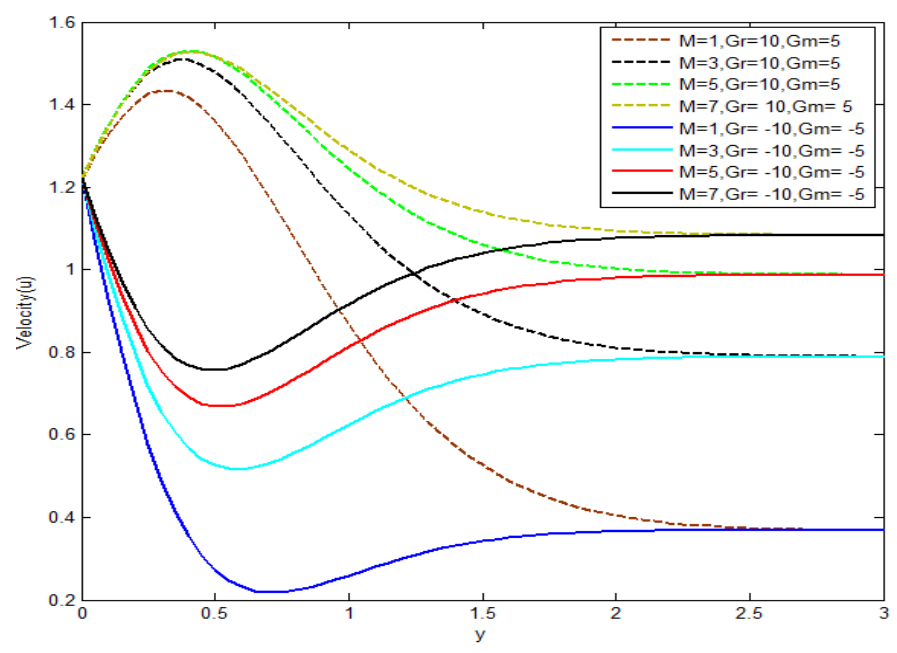

Fig. 3 Velocity profiles for different $M$ when $(K=1), S c=2.01$, So $=5, \operatorname{Pr}=0.71, R=10, a_{0}=0.5, k=0.5, H=4$ and $t=0.4$

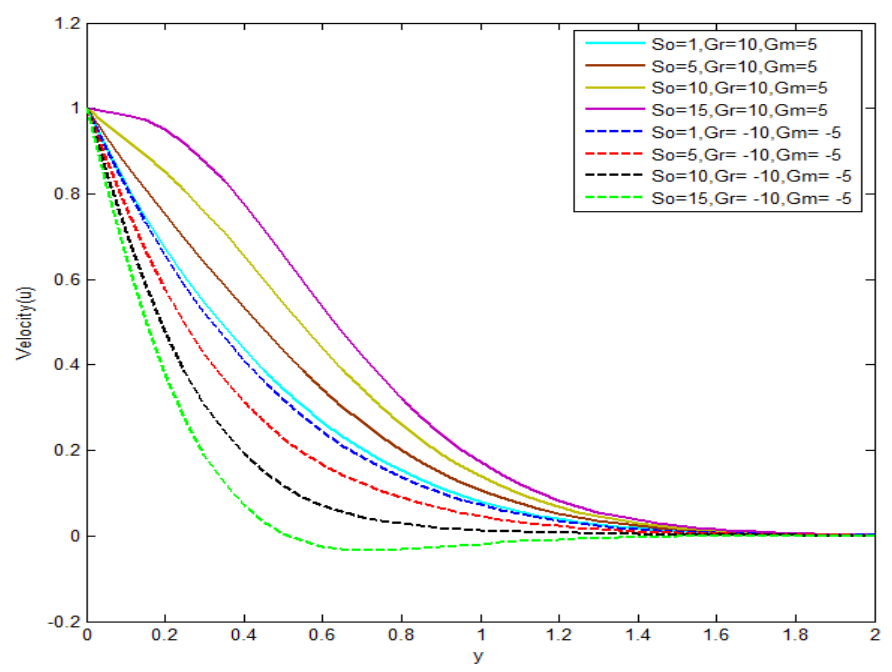

Fig. 4 Velocity profiles for different $S o$ when $(K=0), S c=2.01$, $\operatorname{Pr}=0.71, R=10, H=4, M=3, a_{0}=0, k=0.5$ and $t=0.2$ 


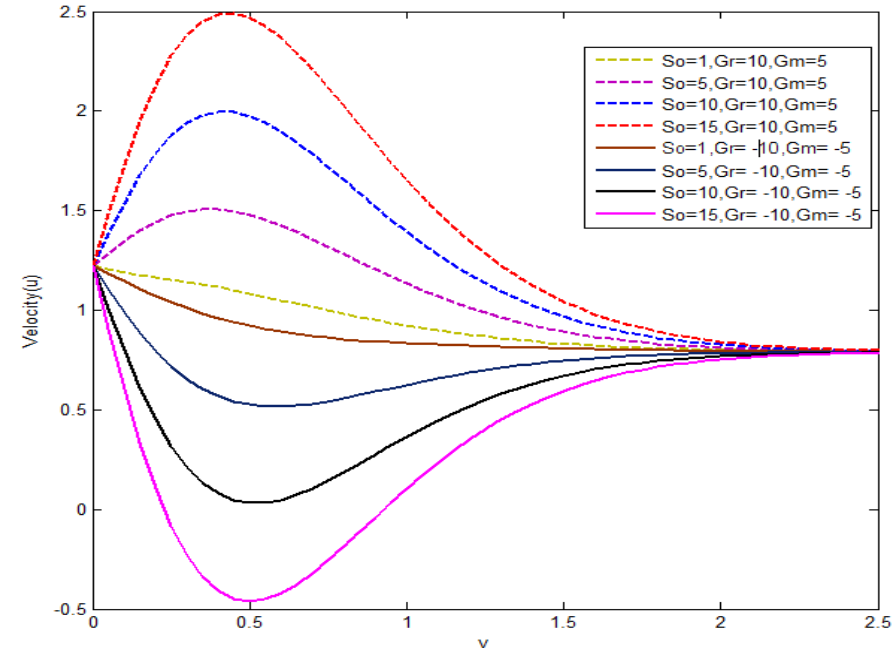

Fig. 5 Velocity profiles for different $S o$ when $(K=1), S c=2.01$, $\operatorname{Pr}=0.71, R=10, H=4, M=3, a_{0}=0.5, k=0.5$ and $t=0.4$.

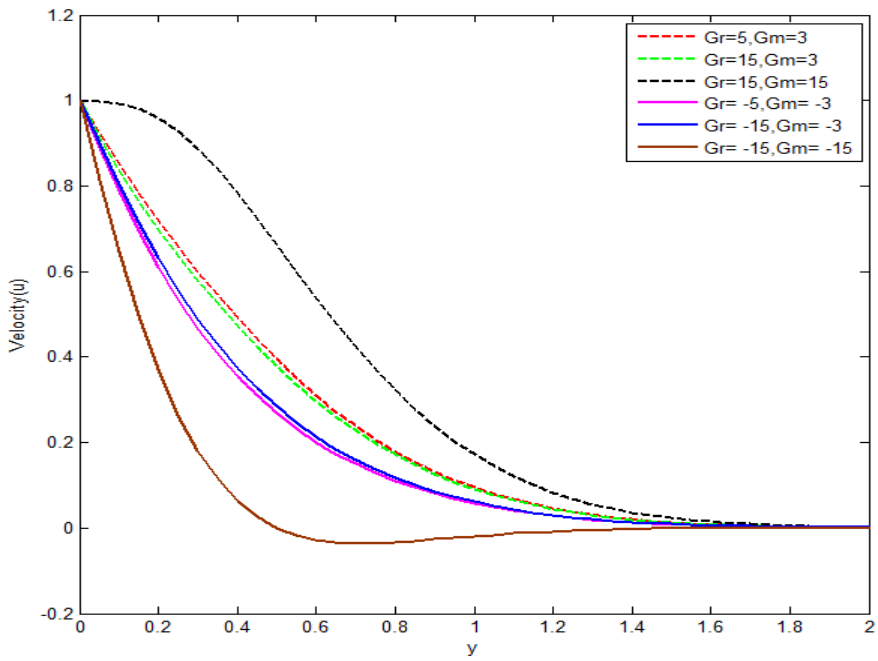

Fig. 6 Velocity profiles for different $G r$ and $G m$ when $(K=0), S c=2.01$, $S o=5, \operatorname{Pr}=0.71, R=10, H=4, M=3, a_{0}=0, k=0.5$ and $t=0$

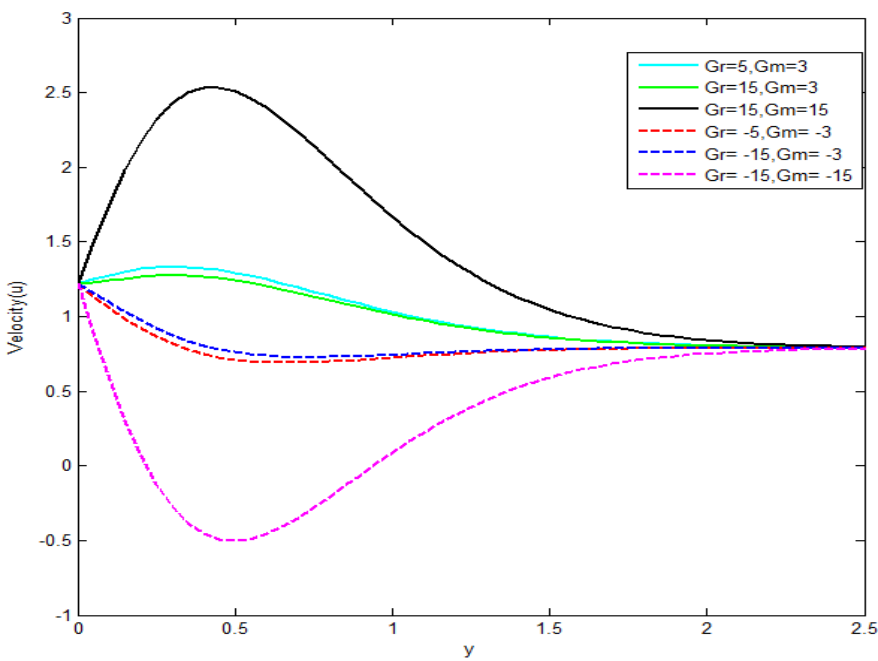

Fig. 7 Velocity profiles for different $G r$ and $G m$ when $(K=1)$, $S c=2.01$, $S o=5 \operatorname{Pr}=0.71, R=10, H=4, M=3, a_{0}=0.5, k=0.5$

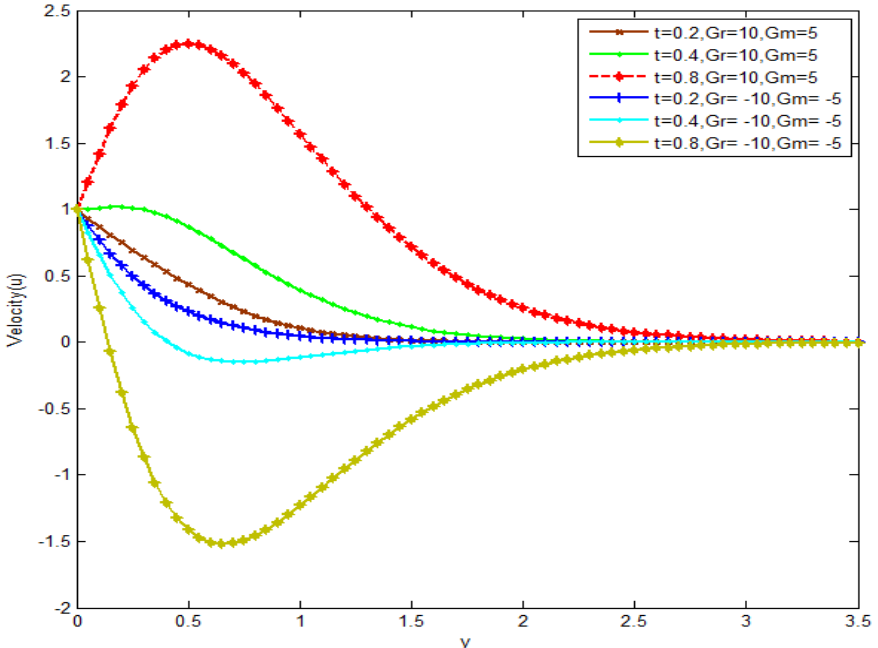

Fig. 8 Velocity profiles for different $t$ when $(K=0), S c=2.01$, So $=5, \operatorname{Pr}=0.71, R=10, H=4, a_{0}=0, M=3$, and $k=0.5$

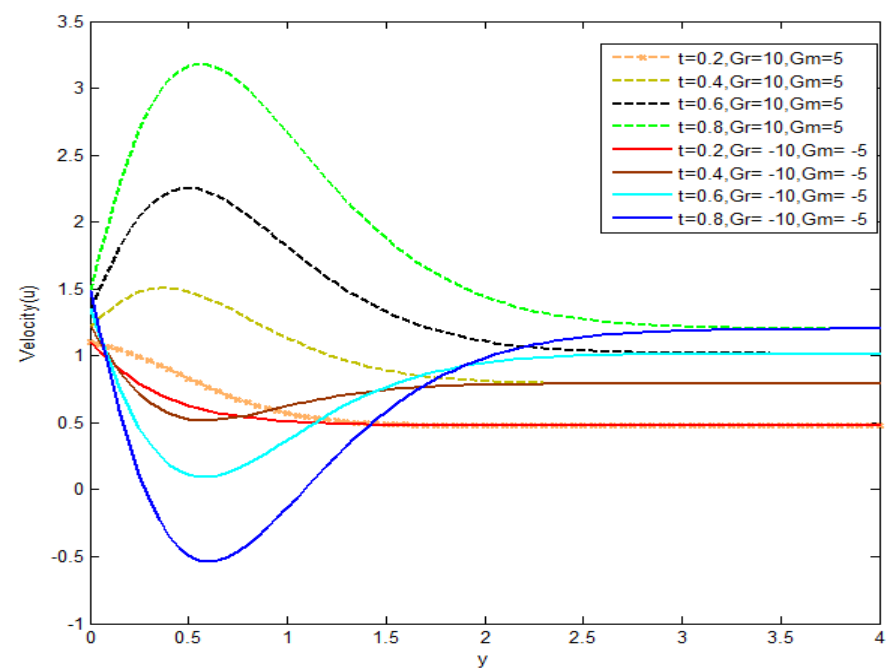

Fig. 9 Velocity profiles for different $t$ when $(K=1), S c=2.01$, So $=5, \operatorname{Pr}=0.71, R=10, H=4, M=3, a_{0}=0.5$ and $k=0.5$

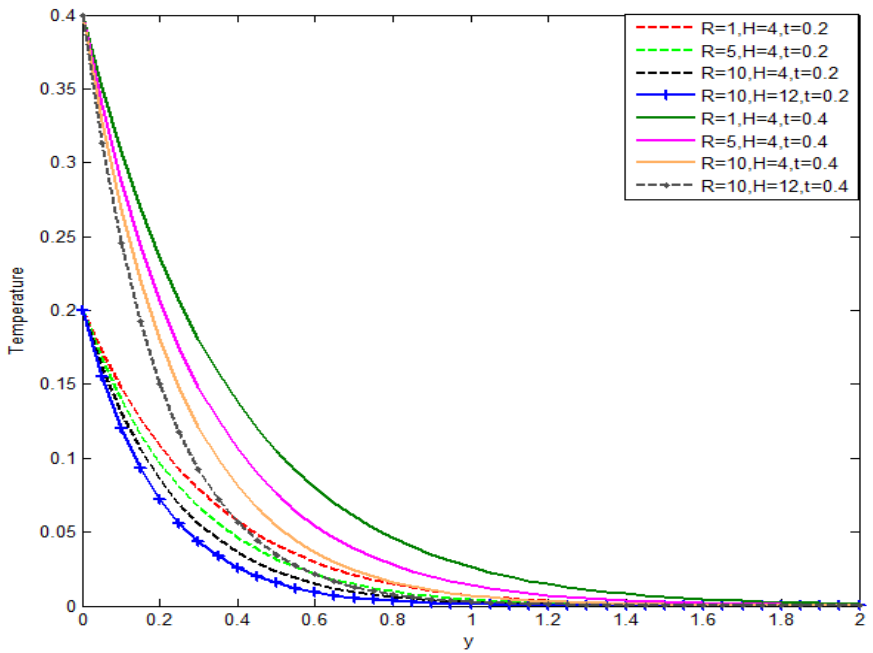

Fig. 10 Temperature profiles for different $R$ and $H$ when $P r=0.7$ 


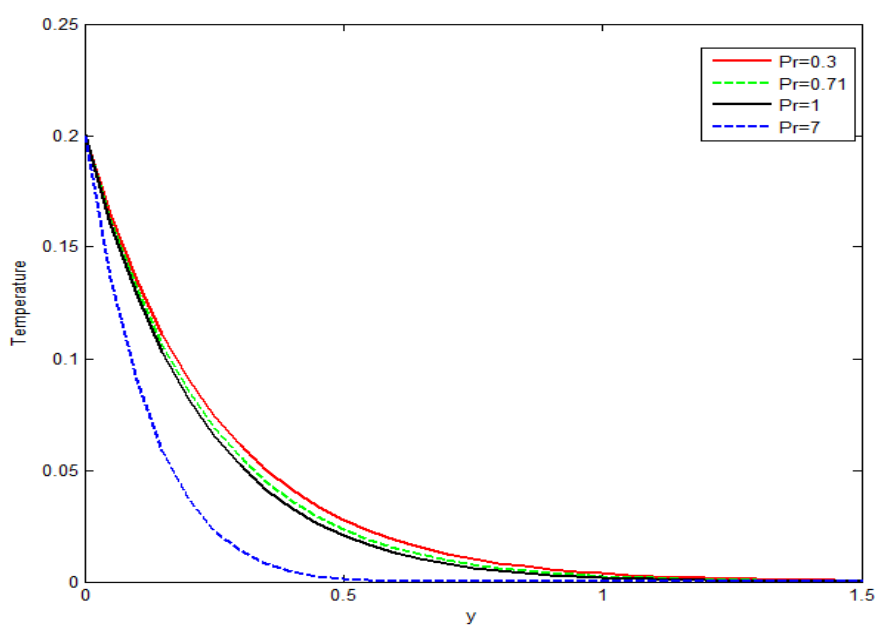

Fig. 11 Temperature profiles for different $\operatorname{Pr}$ when $R=10, H=4$ and $t=0.2$

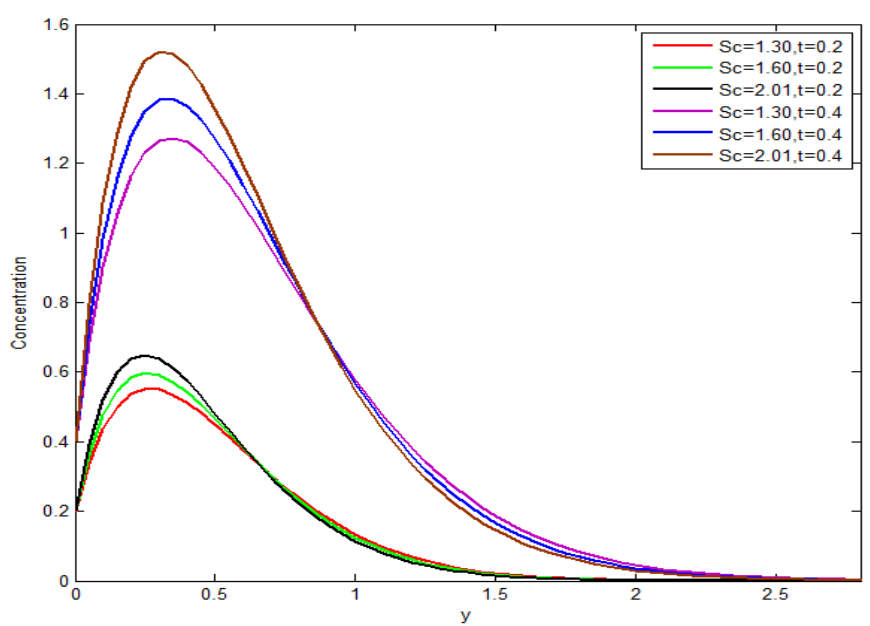

Fig. 12 Concentration profiles for different $S c$ and $t$ when $P r=0.71, R=4, H=1, S o=5, S c=2.01$ and $k=0.5$

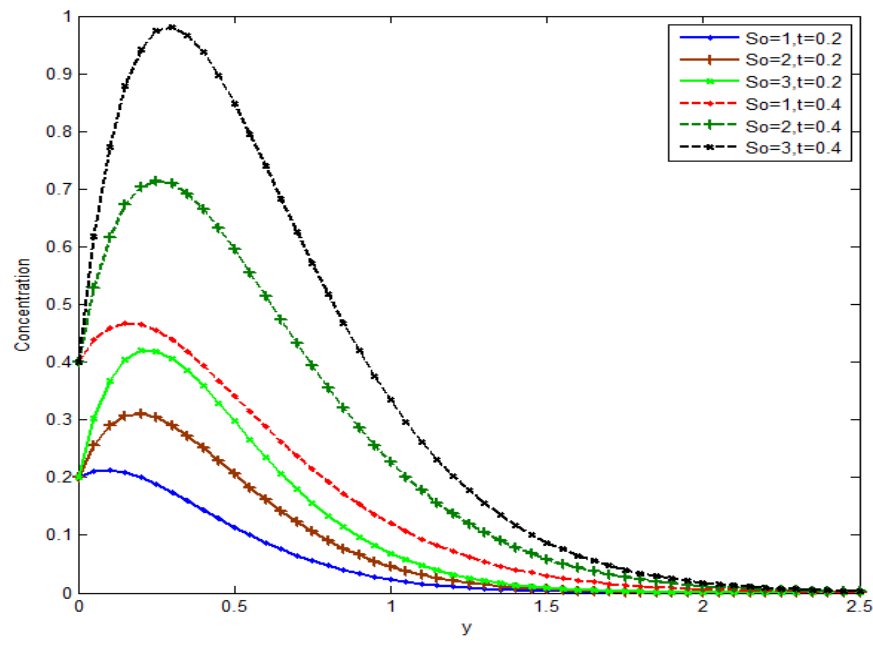

Fig. 13 Concentration profiles for different $S o$ and $t$ when $\operatorname{Pr}=0.71$, $R=4, H=1, S o=5, S c=2.01$ and $k=0.5$

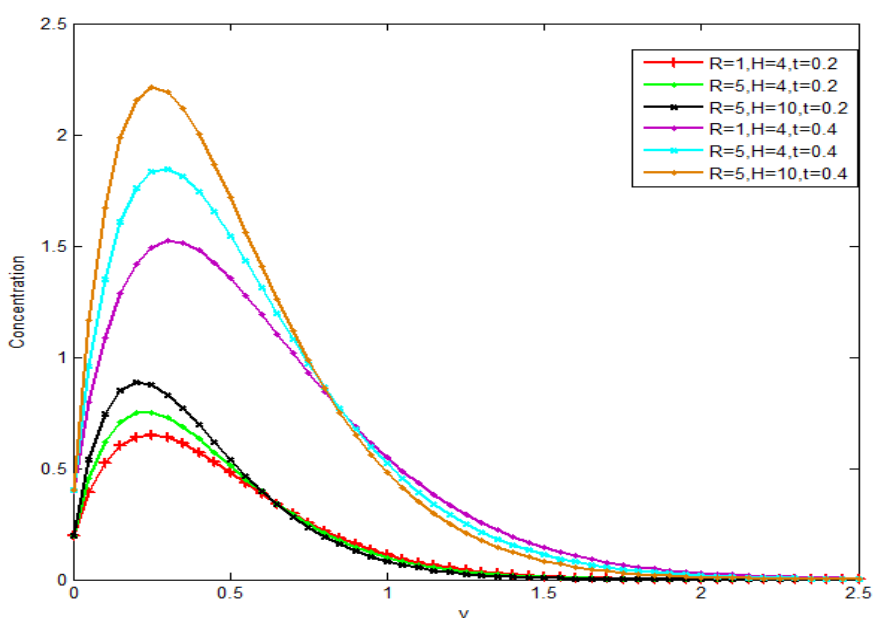

Fig. 14 Concentration profiles for different $R, H$ and $t$ when $\operatorname{Pr}=0.71$, So $=5, S c=2.01$ and $k=0$

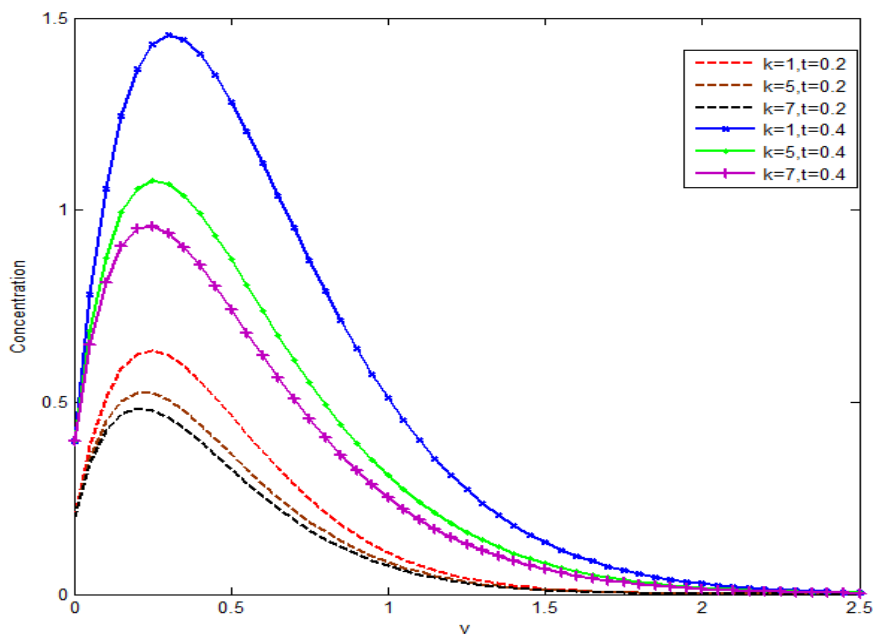

Fig. 15 Concentration profiles for different $k$ and $t$ when $\operatorname{Pr}=0.71$, So $=5, S c=2.01, R=4, H=1$ and $k=0.5$

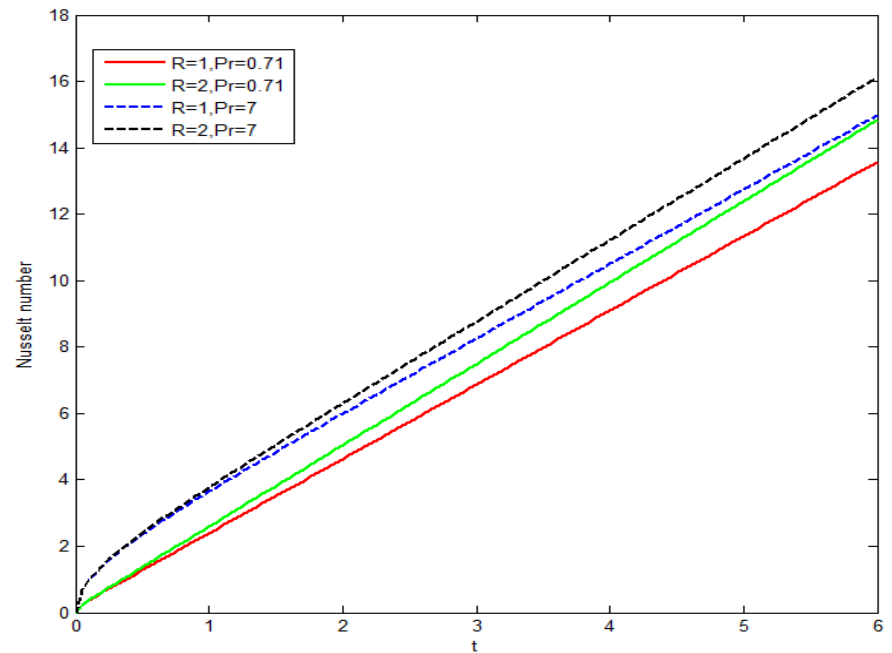

Fig . 16 Nusselt number for different $R$ and $P r$ 


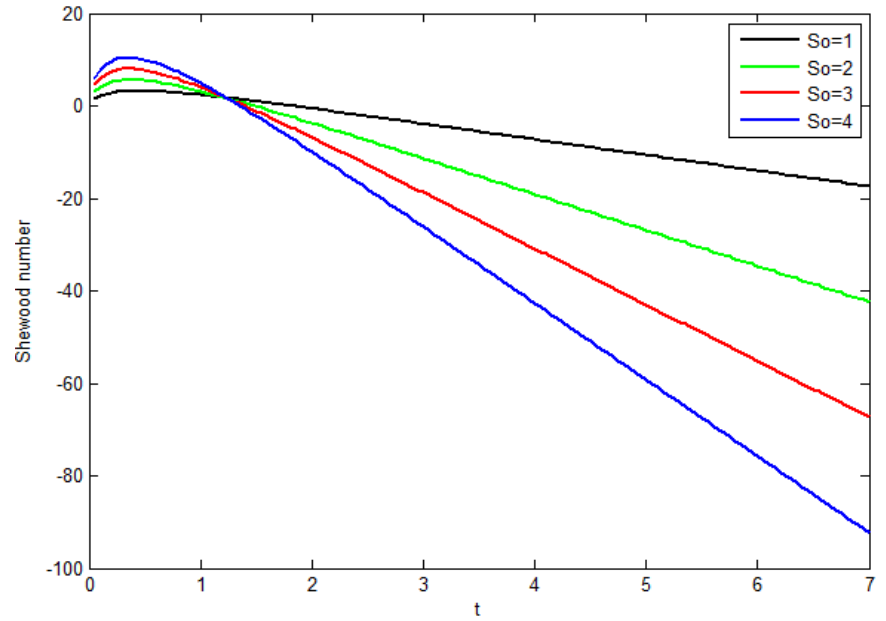

Fig. 17 Sherwood number for different So

Table 1 Velocity for different $R$ when $S c=2.01, \operatorname{Pr}=0.71$, $S o=5, k=0.5$, and $t=0.2$

\begin{tabular}{|l|c|l|l|l|l|l|l|}
\hline \multirow{4}{*}{ Cooling } & \multicolumn{5}{|c|}{$K=0$} & \multicolumn{3}{c|}{$K=1$} \\
\cline { 2 - 8 } of the & $y$ & $R=1$ & $R=5$ & $R=10$ & $R=1$ & $R=5$ & $R=10$ \\
\cline { 2 - 8 } plate & 0.0 & 1.0000 & 1.0000 & 1.0000 & 1.2214 & 1.2214 & 1.2214 \\
& 0.4 & 0.7259 & 0.7391 & 0.7525 & 1.3295 & 1.3892 & 1.4438 \\
& 0.6 & 0.3302 & 0.5211 & 0.5335 & 1.3682 & 1.4429 & 1.5068 \\
& 0.8 & 0.1969 & 0.1991 & 0.3435 & 1.3205 & 1.3793 & 1.4257 \\
& 1.0 & 0.1075 & 0.1072 & 0.1066 & 1.2223 & 1.2567 & 1.2807 \\
Heating & 0.0 & 1.0000 & 1.0000 & 1.0000 & 1.2214 & 1.1255 & 1.1329 \\
of the & 0.2 & 0.6038 & 0.5905 & 0.5771 & 0.9101 & 0.8503 & 1.2214 \\
plate & 0.4 & 0.3384 & 0.3254 & 0.3130 & 0.7068 & 0.6322 & 0.5657 \\
& 0.6 & 0.1805 & 0.1734 & 0.1672 & 0.6223 & 0.5635 & 0.5171 \\
& 0.8 & 0.0926 & 0.0904 & 0.0890 & 0.6159 & 0.5815 & 0.5575 \\
& 1.0 & 0.0455 & 0.0458 & 0.0464 & 0.6465 & 0.6322 & 0.6248 \\
\hline
\end{tabular}

Table 2 Velocity for different $H$ when $S c=2.01, P r=0.71$, $S o=5, k=0.5$ and $t=0.2$

\begin{tabular}{|l|c|l|l|l|l|l|l|}
\hline \multirow{4}{*}{ Cooling } & \multicolumn{5}{|c|}{$K=0$} & \multicolumn{3}{c|}{$K=1$} \\
\cline { 2 - 8 } of the & $y$ & $H=1$ & $H=5$ & $H=10$ & $H=1$ & $H=5$ & $H=10$ \\
\cline { 2 - 8 } plate & 0.2 & 1.0000 & 1.0000 & 1.0000 & 1.2214 & 1.2214 & 1.2214 \\
& 0.4 & 0.5265 & 0.5356 & 0.5446 & 1.4714 & 1.5171 & 1.5595 \\
& 0.6 & 0.3401 & 0.3445 & 0.3485 & 1.4005 & 1.4327 & 1.4606 \\
& 0.8 & 0.1998 & 0.2007 & 0.2013 & 1.2681 & 1.2840 & 1.2963 \\
& 1.0 & 0.1070 & 0.1065 & 0.1058 & 1.1293 & 1.1337 & 1.1357 \\
\hline \multirow{3}{*}{ Heating } & 0.0 & 1.0000 & 1.0000 & 1.0000 & 1.2214 & 1.2214 & 1.2214 \\
of the & 0.2 & 0.5848 & 0.5748 & 0.5643 & 0.8264 & 0.7867 & 0.7478 \\
plate & 0.4 & 0.3200 & 0.3109 & 0.3019 & 0.6036 & 0.5579 & 0.5156 \\
& 0.6 & 0.1706 & 0.1662 & 0.1623 & 0.5422 & 0.5100 & 0.4822 \\
& 0.8 & 0.0897 & 0.0888 & 0.0882 & 0.5701 & 0.5541 & 0.5418 \\
& 1.0 & 0.0460 & 0.0465 & 0.0472 & 0.6284 & 0.6241 & 0.6220 \\
\hline
\end{tabular}

\section{CONCLUSION}

The unsteady free convection chemically reacting fluid flow past an accelerated infinite inclined plate with variable temperature and mass diffusion under the influence of uniform transverse magnetic field when the magnetic lines of force are fixed relative to the fluid or to the plate is studied in two cases. The non-dimensional governing equations are solved with the help of Laplace transform method. The following conclusions have been arrived.

- $\quad$ The fluid velocity decreases as the existence of the magnetic field parameter $M$ becomes stronger.
- An increase in So or $t$ the velocity flow field increases and $G r$ or $G m$ increases the velocity flow field decreases.

- Temperature of the flow field decreases if $R$ or $H$ or $\operatorname{Pr}$ increases.

- Concentration of the flow field increases if $S c$, or So, or $R$, or $H$, or $t$ increases and also concentration decreases with maximizing values of $k$.

- $\quad \mathrm{Nu}$ increments with increasing values of $R$ and Pr.

- $\quad$ Sh diminishes with enhanced values of So

\section{NOMENCLATURE}

$a^{*}$
$H^{*}$
$B_{0}$
$C^{\prime}$
$C_{W}^{\prime}$
$C_{\infty}^{\prime}$
$C$
$C_{p}$
$D$
$D_{1}$
$g$
$G r$
$G m$
$M$
$N u$
$\operatorname{Pr}$
$q_{r}$
$R$
SC

Absorption coefficient $\left(\mathrm{cm}^{-1}\right)$

Accelerated parameter $\left(\mathrm{msec}^{-2}\right)$

Heat source parameter $\left(\mathrm{w} / \mathrm{m}^{2} \mathrm{~K}\right)$

External magnetic field (A. $\left.\mathrm{m}^{2}\right)$

Species concentration

$C_{W}^{\prime} \quad$ Concentration of the plate

$C_{\infty}^{\prime} \quad$ Concentration of the fluid far away from the plate

C Dimensionless concentration $\left(\mathrm{kg} / \mathrm{m}^{3}\right)$

$C_{p} \quad$ Specific heat at constant pressure (J/kg.K)

Chemical molecular diffusivity (J/kg.K)

Coefficient of thermal diffusivity

Acceleration due to gravity $\left(\mathrm{ms}^{-2}\right)$

Gm Mass Grashof number

$M \quad$ Magnetic field parameter $\left(\mathrm{Am}^{-1}\right)$

$\mathrm{Nu} \quad$ Nusselt number

Pr Prandtl number

$R$

Sc

So

Sh

$T^{\prime}$

$T_{W}^{\prime}$

$T_{\infty}^{\prime}$

$t^{\prime}$

$t$

$u^{\prime}$

$u_{0}$

Radiative heat flux in the $y$-direction $\left(\mathrm{wm}^{-2}\right)$

Radiative parameter $\left(\mathrm{cm}^{-2}\right)$

Schmidt number

Soret number

Sherwood number

Temperature of the fluid near the plate

Temperature of the plate

Temperature of the fluid far away from the plate

Time

Dimensionless time (s)

Velocity of the fluid in the $x^{\prime}$-direction

Velocity of the plate

Dimensionless velocity $\left(\mathrm{ms}^{-1}\right)$

Co-ordinate axis normal to the plate

$y \quad$ Dimensionless Co-ordinate axis normal to the plate Greek symbols

$k \quad$ Thermal conductivity of the fluid (W/m.K)

$\alpha \quad$ Thermal diffusivity $\left(\mathrm{Wm}^{2} \mathrm{j}^{-1}\right)$

$\beta \quad$ Volumetric coefficient of thermal expansion

$\beta^{*} \quad$ Volumetric coefficient of expansion with concentration

$\mu \quad$ Coefficient of viscosity $\left(\mathrm{m}^{2} \mathrm{~s}^{-1}\right)$

$v \quad$ Kinematic viscosity $\left(\mathrm{m}^{2} \mathrm{~s}^{-1}\right)$

$\rho \quad$ Density of the fluid $\left(\mathrm{kgm}^{-3}\right)$

$\sigma \quad$ Electric conductivity $\left(\mathrm{Sm}^{-1}\right)$

$\theta \quad$ Dimensionless temperature (K)

erf Error function

erfc Complementary error function 


$$
\begin{array}{ll}
\text { Subscripts } & \\
w & \text { Conditions on the wall } \\
\infty & \text { Free stream conditions }
\end{array}
$$

\section{REFERENCES}

Cramer, K.R., and Pai, S.I.,1973, Magneto Fluid Dynamics for Engineers and Applied Physicists (McGraw-Hill Book Company, New York).

Eekert, E.R.G., and Drake, R.M., 1972, Analysis of Heat and Mass Transfer, ( Mc Graw-Hill Book co, New York).

Gebhart, B., 1971, Heat Transfer ( ${ }^{\text {nd }}$ edition), (Mc Graw-Hill Book co, New York).

Alam, M.M., and Sattar, M. A., 1999, "Transient MHD Heat and Mass Transfer Flow with Thermal Diffusion in a Rotating System,” J. Energy Heat Mass transfer. 21 m, 9-21.

Alam, M.S., Rahman, M.M., and Maleque, M.A., 2005, "Local Similarity Solutions for Unsteady MHD Free Convection and Mass Transfer Flow Past an Impulsively Started Vertical Porous Plate with Dufour and Soret effects,” Thammasatint.j.sci.tech. 10(3), 1-8.

Alam,M.S., Rahman, M.M., and Samad, M.A., 2006, "Numerical Study of the Combined Free-Forced Convection and Mass Transfer Flow Past a Vertical Porous Plate in a Porous Medium with Heat generation and Thermal Diffusion, Nonlinear”. Anal. Model. Control 11(4), 331-343.

Chandran, P., Sacheti, N.C., and Singh, A.K., 1998, "Unsteady Hydro magnetic Free Convection Flow with Heat Flux and Accelerated Boundary Motion,” J. Phys. Soc. Japan. 67, 124-129.

http://dx.doi.org/10.1143/JPSJ.67.124

Das, U.N., Deka, R.K., and Soundalgekar, V.M., 1996, "Radiation Effects on Flow Past an Impulsively Started Vertical Infinite Plate," J.theo. Mech. 1, 111-115.

Hossain, M. A., and Takhar, H.S., 1996, "Radiation Effect on Mixed Convection along a Vertical Plate with Uniform Surface Temperature,” Heat and Mass Transfer. 31, 243-248.

http://dx.doi.org/10.1007/bf02328616 .

Jha,B. K., and Singh, A. K., 1990, "Soret Effects on Free-Convection and Mass Transfer Flow in the Stokes Problem for an Infinite Vertical Plate,” Astrophys. Space Sci. 173(2), 251-255.

http://dx.doi.org/10.1007/bf00643934

Kafoussias, N. G., 1992, "MHD Thermal Diffusion Effects on Free Convective and Mass Transfer Flow over an Infinite Vertical Moving Plate”. Astrophys. Space Sci. 192(1), 11-19.

http://dx.doi.org/10.1007/bf00653255

Kumar,A.G.V., and Vijaya Kumar Varma,S., 2011, “Thermal Diffusion and Radiation Effects on Unsteady MHD Flow Past an Impulsively Started Exponentially Accelerated Vertical Plate with Variable Temperature and Variable Mass Diffusion," Int. J. of Applied Mathematical Analysis and Applications, Vol.6, No.1- 2, pp.169-192.
Kumar, A.G.V., Rajasekarhara Goud, Y., and Vijaya Kumar Varma, S., 2012 ,"Thermal Diffusion and Radiation Effects on Unsteady MHD Flow Past an Exponentially Accelerated Vertical Plate with Variable Temperature and Mass Diffusion in the Presence of Heat Source/Sink". Elixer Appl. Math. 49, 9948-9954

Kumari,M., and Nath ,G., 1999, "Development of Two-Dimensional Boundary Layer with an Applied Magnetic Field due to an Impulsive Motion,” Indian J. pure Appl. Math. 30, 695- 708.

Muthucumaraswamy, R., and Janakiraman, B., 2006, "MHD and Radiation Effects on Moving Isothermal Vertical Plate with Variable and Mass Diffusion,” Theo. Appl. Mech. 33(1), 17-29.

http://dx.doi.org/10.2298/tam0601017m

Narahari, M., and Debnath, L., 2013, “Unsteady Magneto hydrodynamic Free Convection Flow Past an Accelerated Vertical Plate,” Z.Angew.Math. Mech. 93, No. 1, 38-49. http://dx.doi.org/10.1002/zamm.201200008

Pera, L., and Gebhart, B., 1971, "On the Stability of Laminar Plums: Some Numerical Solution and Experiments,” Heat Mass Transfer.Int.J. 14 ,Issu 7, 975 to 984. http://dx.doi.org/10.1016/0017-9310(71)90123-2

Raptis, A., and Singh, A.K., 1983, "MHD Free Convection Flow past an Accelerated Vertical Plate," Int. Communication Heat and Mass Transfer. 10(4), 313-321. http://dx.doi.org/10.1016/0735-1933(83)90016-7

Rajesh, V., and Varma, S.V.K., 2009, "Thermal Diffusion and Radiation Effects on MHD Flow Past an Infinite Vertical Plate with Variable Temperature and Mass Diffusion," JP Journal of Heat and Mass Transfer. 3 (1), 1- 72.

Raptis, A., and Perdikis, C., 1999, "Radiation and Free Convection Flow Past a Moving Plate,” Int. J.Appl Mech. Eng. 4, 817- 821.

Soundalgekar, V.M., 1977,” Free Convection Effects on the Stokes Problem for an Infinite Vertical Plate” J. Heat Transfer, 99(3), 499501.

http://dx.doi.org/10.1115/1.3450729

Soundalgekar, V.M., Gupta,S.K., and Birajdar ,N.S., 1979, “ Effects of Mass Transfer and Free Convection Currents on MHD Stokes Problem For a Vertical Plate,” Nuclear Eng. Des. 53 (3), 339-346. http://dx.doi.org/10.1016/0029-5493(79)90060-8

Soundalgekar, V.M., Patil, M.R., and Jahagirdar, M.D., 1981,“MHD Stokes Problem For a Vertical Plate with Variable Temperature," Nuclear Eng. Des. 64 (1), 39-42.

http://dx.doi.org/10.1016/0029-5493(81)90030-3

Soundalgekar, V.M. and Takhar, H.S., 1993, "Radiation Effects on Free Convection Flow Past a Semi-infinite Vertical Plate,” Model. Measure. Control, B51, 31-40.

Stokes, G.G., 1851, "On the Effect of the Internal Fraction of Fluids on the Motion of a Pendulum Trans,” Camb. Phil. Soc. 9, pp.8-106.

Tokis, J.N., 1985, "A class of Exact Solutions of the Unsteady Magneto hydrodynamic Free Convection Flows," Astrophysics. Space Sci. 112(2), 413-422. http://dx.doi.org/10.1007/bf00653524 